\title{
El patrimonio como objeto de estudio interdisciplinario. Reflexiones desde la educación formal chilena
}

\author{
Macarena Ibarra \\ Pontificia Universidad Católica de Chile Santiago, Chile. \\ Email:mibarra@uc.cl \\ Umberto Bonomo \\ Pontificia Universidad Católica de Chile Santiago, Chile. \\ Email: ubonomo@uc.cl \\ Cecilia Ramírez \\ Pontificia Universidad Católica de Chile Santiago, Chile. \\ Emaildramirev@uc.cl
}

\begin{abstract}
Resumen: La investigación busca contribuir a la educación patrimonial desde la consideración del patrimonio como un fenómeno amplio, integrador y que se actualiza en forma permanente. Para ello, indaga en sus raíces multidisciplinares e interdisciplinares en la medida que aborda diferentes dimensiones del espacio habitado por una sociedad -tanto en su ámbito construido como natural y en su dimensión material e inmaterial- y que surge de ciertos acuerdos culturales de valoración. Con el fin de realizar una aproximación a la educación patrimonial en su dimensión interdisciplinar, se examina la naturaleza de dicho objeto de estudio desde dos dimensiones. La primera, desde la aproximación integral de su ámbito de conocimiento que lo invoca a ser entendido desde diversas disciplinas por distintos especialistas. La segunda, desde la forma en que esta materia se plasma en los actuales planes y programas establecidos por el Ministerio de Educación chileno en cuanto objeto de estudio compartido por diversas asignaturas. Desde esta doble mirada es que se propone avanzar en el fortalecimiento de la educación patrimonial. ${ }^{1}$
\end{abstract}

Palabras clave: patrimonio, educación patrimonial, estudio interdisciplinar.

\section{Patrimony as an interdisciplinary object of study. An analysis from the Chilean formal education}

\begin{abstract}
The research aims to contribute to patrimonial education by considering patrimony as a broad, inclusive and dynamic phenomenon. For that, it searches on its multidisciplinary and interdisciplinary roots as it addresses the different dimensions of the space inhabited by a society -both natural and built environment, material and immaterial- which emerges as a result of certain cultural
\end{abstract}


agreements of appreciation. In order to address heritage education on its interdisciplinary basis, the object of study of patrimony is examined in two dimensions. The first one considers that the different approaches towards the concept obliges to consider it from different disciplines and specialists. The second one, from the way in which contents appears in current Chilean curriculum set up by the Ministry of Education as an object of study shared by different assignments. From this double perspective, the research intends to contribute on strengthening patrimonial education.

Key words: patrimony, patrimonial education, interdisciplinary study.

\section{O patrimônio como objeto de estudo interdisciplinar. Reflexões a partir da educação formal chilena}

Resumo: A pesquisa tem como objetivo contribuir para a educação patrimonial a partir da consideração do património como um fenômeno amplo, inclusivo e que se atualiza permanentemente. Para fazer isso, investiga suas raízes multidisciplinares e interdisciplinares na medida em que aborda diferentes dimensões do espaço habitado por uma sociedade - tanto no seu âmbito construído e natural, quanto na sua dimensão tangível e intangível- decorrente de certos acordos de valorização cultural. Com a finalidade de realizar uma abordagem à educação patrimonial na sua dimensão interdisciplinar, se analisa a natureza desse objeto de estudo a partir de duas dimensões. A primeira, a partir da aproximação integral de sua área de conhecimento que a invoca para ser entendida desde diversas disciplinas por diferentes especialistas. A segunda, desde a forma como esta questão se reflete nos atuais planos e programas estabelecidos pelo Ministério da Educação chileno em quanto objeto de estudo compartilhado por diversas matérias. Desde esta visão dupla propomos avançar no fortalecimento da educação patrimonial.

Palavras-chave: patrimônio, educação patrimonial, estudo interdisciplinar

$* * *$

\section{El patrimonio: un fenómeno dinámico e integrador}

"Si nuestros niños de hoy valoran desde pequeños su patrimonio, la protección del mismo en el futuro será un tema sensible y defendido con tanta energía como el medioambiental.” (Acuña 2009: 10)

¿Qué es el patrimonio? Abordar esta amplia interrogante implica reflexionar sobre la sociedad y el espacio que ésta habita e interrogar sobre la cultura y el territorio. Por ello, hacerse cargo de la pregunta -¿qué es el patrimonio?- resulta esencial aún cuando no exista una respuesta acabada ni desde su propio concepto ni desde los diversos criterios del término. Esta reflexión propone abordar el concepto críticamente a la vez de entenderlo como parte de un fenómeno en el cual convergen diferentes miradas y, por tanto, varias disciplinas. Adicionalmente, problematizar este concepto permite relevar las complejas respuestas frente a la valoración, gestión y protección del patrimonio. 
La propia etimología del concepto da cuenta de que el término patrimonio evoca la noción de herencia y de bien. ${ }^{2}$ La idea de herencia o de legado implica reconocer que el patrimonio pertenece a todos y que, por tanto, existe un derecho sobre éste, mientras la idea de bien, alude al valor asociado del mismo. Así, la etimología, anuncia el grado de complejidad del concepto, difícil de superar, en cuanto obliga a considerar interrogantes tales como ¿cuáles son esos bienes? Adicionalmente, la noción misma del término ha evolucionado en los últimos años, desde una visión "monumentalista" a una forma de comprender el patrimonio desde la vida cotidiana y modos de vida mientras la memoria adquiere importancia. A nivel nacional, estos cambios generales también se perciben mientras los monumentos nacionales comienzan a abandonar su carácter puramente conmemorativo e incluir elementos de la memoria.

Aun cuando existen diferentes consideraciones sobre las formas de considerar el patrimonio parece ser que hay consenso en relación a su reconocimiento como construcción social. (Dormaels 2011) De ahí que el sujeto, -el individuo o la sociedad- sea el protagonista de lo que se ha denominado como patrimonialización o proceso mediante el cual se reconoce y otorga valor a un objeto.

Los "objetos" considerados como patrimoniales pueden ser de distinta índole. Mientras el patrimonio natural oficialmente protegido puede incluir reservas, parques o monumentos naturales, el patrimonio cultural comprende todo aquello que pertenece a una cultura. A su vez el patrimonio cultural puede ser material o tangible (tal como objetos y lugares); o inmaterial o intangible (tal como creencias, fiestas, tradiciones y oficios). En definitiva se trata de "bienes" diversos agrupados como relevantes para una comunidad, que los disfruta y para quienes tiene un significado. Así, su valor o significación puede ser carácter histórico, social, científico, arquitectónico, urbano o de los más diversos aspectos. Choay (Choay 2007) define la noción de patrimonio urbano y arquitectónico como aquel patrimonio edificado en cuanto marco de vida de un grupo y de un individuo y que es parte del patrimonio cultural.

No obstante tradicionalmente se ha intentado clasificar el patrimonio en sus diversas categorías, cabe destacar que los estudios avanzan hoy hacia una mayor integración de los distintos tipos de patrimonio en pos de comprender en términos amplios cómo estos son parte de modos de vida de una comunidad. ${ }^{3}$ Este hecho debiera tener una positiva repercusión en su resguardo en la medida que, por ejemplo, la protección de un pueblo típico como la Tirana contribuye a la protección de la tradicional fiesta que se celebra en torno a este pueblo y que se constituye como parte del patrimonio inmaterial. Otro caso de interés, han sido proyectos para resguardar los parques urbanos bajo la premisa de que éstos no son sólo parte del patrimonio natural sino también cultural de una ciudad. ${ }^{4}$

Una parte del patrimonio está oficialmente declarado. En Chile, existen cuatro categorías de protección desde el Estado, a cargo del Consejo de 
Monumentos Nacionales (CMN) amparados por la ley 17.288 de Monumentos Nacionales. Tales categorías constituyen los monumentos nacionales de Chile son los monumentos históricos, monumentos públicos, sitios arqueológicos y zonas típicas y pintorescas. ${ }^{5}$ A nivel local existe otro mecanismo que se utiliza para proteger los inmuebles de conservación histórica (ICH) y las zonas de conservación histórica $(\mathrm{ZCH})$ según la Ordenanza General de Urbanismo y Construcción, que depende de los Planes Reguladores Comunales. Una tercera protección oficial del patrimonio chileno es la que realiza UNESCO a través de los sitios declarados como Patrimonio Mundial (SPM) y cuyo resguardo queda a cargo del CMN.

Más allá de lo que está oficialmente protegido en Chile, -sea por parte del Estado, a nivel local o a través de los acuerdos de protección de UNESCO- patrimonio como tal significan todos aquellos objetos que un grupo valor y reconoce como parte de su legado. Resulta importante reconocer la existencia de un patrimonio no oficialmente protegido en cuanto su resguardo se transforma en un desafío mayor por no contar con una normativa que regule su destino. En este contexto, promover la educación patrimonial adquiere aún mayor relevancia.

Por otra parte, debido a los cambios que la valoración patrimonial puede sufrir en los distintos marcos temporales y espaciales, es que el concepto no sólo se construye en forma permanente sino que está sujeto a constantes cambios que se vinculan a significaciones que van desde el contexto socio-cultural a la estética dominante. Según Choay, las preguntas claves sobre el patrimonio histórico tienen que ver con el sentido a un culto lo cual revela una relación entre la sociedad y los interrogantes que la habitan. (Choay 2007) Las ideas de herencia y de valor asociadas al patrimonio, no sólo ilustran su subjetividad sino que indican cómo está en permanente construcción. De este modo, la connotación cultural del patrimonio ha llevado a ampliar sus propios límites cobrando especial relevancia la concepción que Norá plantea como “una idea comprensiva y vaga” (Norá 2009).

La discusión del significado del patrimonio, se puede comparar con la discusión del significado de las imágenes, que según Burke, implica plantear una pregunta fundamental: ¿ significado para quién? (Burke 2001: 178) Las distintas miradas del patrimonio tienen que ver con las imágenes: el patrimonio y su valoración se vinculan al efecto visual que el objeto produce en el sujeto. En este sentido, si el patrimonio depende de la mirada del objeto, pueden existir distintos patrimonios de acuerdo a los distintos significados del objeto o del intangible. Por ejemplo, el antiguo edificio de la Caja del Seguro Obrero en el centro de Santiago -actual Ministerio de Justicia- se observa y concibe distinto antes y después de la matanza del año 1938, acontecimiento que torna a este edificio como emblemático de un momento político y social de la historia del país. ${ }^{6}$

Las diferentes miradas, desde lo personal a lo colectivo, desde la mirada de un niño a la de un adulto, desde un técnico a un activista, desde 
un arqueólogo a un historiador, no hacen más que verificar la diversidad de enfoques con que pueden tratarse los estudios sobre el patrimonio. Existen una serie de disciplinas involucradas con este fenómeno y por tanto de métodos para abordarlo. Es así como el patrimonio aparece no sólo como un concepto dinámico sino también como un fenómeno problemático y, como se verá, multidisciplinar e interdisciplinar. Concebir el patrimonio como un fenómeno, implica examinarlo, no como un objeto que está a cargo de una sola disciplina con un objeto de estudio y con métodos relacionados a ella, sino un fenómeno que está a cargo de diferentes disciplinas.

Así como hay distintas miradas del patrimonio, hay diferentes formas de representarlo: la fotografía, los planos, artefactos, colecciones literarias, composiciones musicales, arte pictórico, entre otros, son distintas formas tienen que ver con la aproximación disciplinar que se otorgue al fenómeno pues cada disciplina cuenta con su método, documentos y fuentes para el intercambio del conocimiento.

\section{El patrimonio: un campo de estudio compartido}

En la línea de un estudio en desarrollo que se concentra en la educación y formación patrimonial, desde las bases, esta reflexión examina el patrimonio como objeto de estudio que aglutina el quehacer e interés de varias disciplinas. Bajo este interés se indaga en el objeto de estudio del patrimonio y en su naturaleza compartida por distintas disciplinas, para posteriormente examinarlo desde los procesos de enseñanza y aprendizaje en el mundo escolar.

Una propuesta tentativa de lo que se entiende por objeto de estudio, es concebirlo como un "recorte" de la realidad con el fin de aprehenderlo en forma científica o, dicho de otro modo, como resultado final del proceso investigativo (Barriga 2003). Si por patrimonio, se entiende un objeto con mérito de ser protegido dado el valor que le atribuye una comunidad, la diversidad de valores asociados también varían de acuerdo a los distintos tipos de objetos en cuestión. En este proceso de reconocimiento y valoración, participan varias disciplinas.

Más allá de reconocer la existencia de varias fuentes disciplinares del patrimonio, habría que reflexionar sobre la forma en que éstas se articulan ¿Cuál es el paso de la autonomía disciplinar a un estudio multidisciplinario? ¿Cómo es esa frontera entre lo multidisciplinar y lo interdisciplinar en la aproximación a los estudios patrimoniales?

Pese a que las fronteras disciplinares pueden ser complejas, se debe reconocer que cada disciplina cuenta con un objeto de estudio que la define. Así, por ejemplo, la Arquitectura estudia, diseña y construye el hábitat artificial para el hombre; la Música se encarga de decodificar el lenguaje musical en su aspecto sintáctico y semántico para entender su significado; la Geografía se ocupa de las relaciones entre el hombre y el espacio; la 
Literatura estudia y crea obras, orales y escritas, desde el lenguaje; y la Historia estudia los hechos del pasado (Carr 1961: 73). Si se considera estas cinco disciplinas, se podría sostener que cada una de ellas cuenta con un campo de conocimiento específico que se desarrolla a partir de su objeto estudio a través de metodologías específicas. (Ver Figura 1)

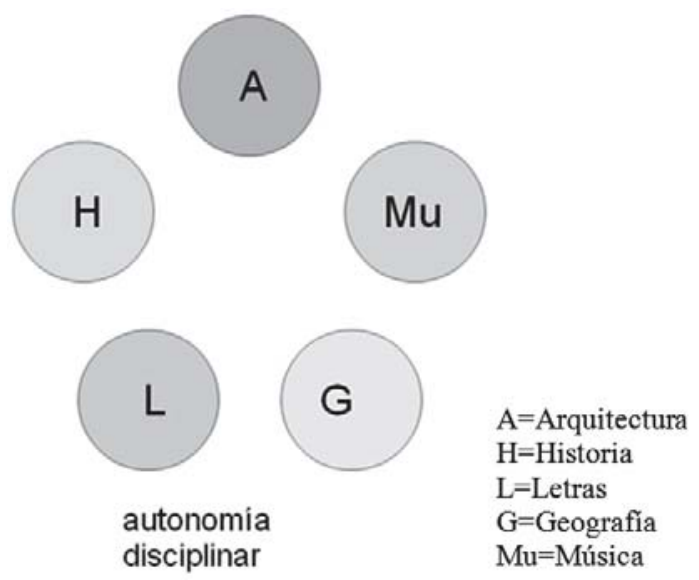

Fig. 1 Autonomía disciplinar

Fuente: Elaboración propia

No obstante, cada disciplina cuenta con su campo de conocimiento, cabe señalar que sus límites son, más que fronteras, espacios, espacios difusos y permeables que permiten el diálogo con otras disciplinas (Ibarra, Ramírez, Bonomo 2011). Es este el espacio que explica la posible articulación entre disciplinas que, para los estudios del patrimonio, es evidente. Es justamente allí donde el límite de las disciplinas y sus objetos de estudios se hacen más difusos facilitando una superposición de objetos de estudios que serán compartidos por más de una disciplina. Por ejemplo, si se estudia la evolución de la relación entre el hombre y su hábitat doméstico, las viviendas, parte de las cuales constituye el patrimonio habitacional del siglo veinte, se puede evidenciar cómo la arquitectura no termina por explicar ni su proceso ni de dar las claves para una potencial valoración. Se debe recurrir a la historia para entender una serie de fenómenos sociales, culturales y políticos asociados a estas piezas.

De esta simple integración entre la arquitectura y la historia podría observarse el mérito de los primeros conjuntos habitacionales modelos construidos en Santiago, tal como la Población Huemul I proyectada por Ricardo Larraín Bravo a principio del siglo XX, que además de proponer un nuevo modo delos 
habitacional intentaba solucionar los problemas higiénicos de la población urbana (Hidalgo 2004: 53). Así, se podría añadir una mirada adicional que tiene que ver con la literatura asociada a estos espacios, tanto como inspiradores de la misma como fuentes para su conocimiento. En el caso de la misma Población Huemul, Gabriela Mistral no sólo tuvo una casa allí sino que también le dedicó a ese conjunto su poema Leche. (Ibarra, Bonomo 2012)

En este sentido, las fuentes disciplinares del patrimonio son tantas como tantos sean los "lentes" con los cuales se observe el objeto. Y es justamente de esta particularidad del patrimonio como objeto de estudio, desde donde arranca un encuentro entre disciplinas. Dicho encuentro es lo que Sotolongo y Delgado (2006) refieren como diálogo entre saberes los cuales apuntan a una convergencia en términos conceptuales, metodológicos y metódicos, sea multidisciplinar, interdisciplinar o transdisciplinar.

Si cada una de las disciplinas mencionadas se ocupa, en su ámbito disciplinar específico del estudio de una porción del patrimonio, entonces se facilita el cruce de distintos saberes y, por tanto, el diálogo entre disciplinas. De alguna forma, se va construyendo una dinámica multidisciplinar (Ver Figura 2). La Historia al ocuparse del pasado contiene en su ámbito de estudio una parte del patrimonio, más allá de que el patrimonio sea considerado como un bien que se hereda del pasado. Retomando el mismo caso, la arquitectura, en su estudio e intervención de obras, edificios o ciudades, por mimesis o contraste, incorpora en su quehacer parte del patrimonio construido que se conoce como patrimonio arquitectónico. De este modo, las distintas disciplinas se ocupan de manera independiente del mismo objeto de estudio, el patrimonio, constituyendo una aproximación multidisciplinaria.

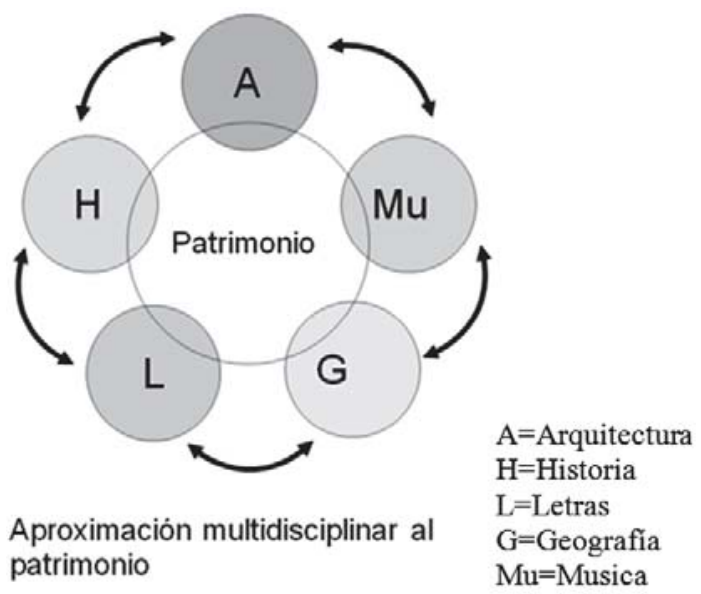

Fig. 2 Aproximación multidisciplinar

Fuente: Elaboración propia 
Mas se ha sostenido que los límites de cada disciplina son espacios permeables que facilitan la superposición y encuentro disciplinar. Cuando desde la aproximación multidisciplinar se crean espacios con campo de conocimiento compartido, se favorece el acercamiento entre las disciplinas y se avanza hacia un ámbito de trabajo interdisciplinario (Ver Figura 3).
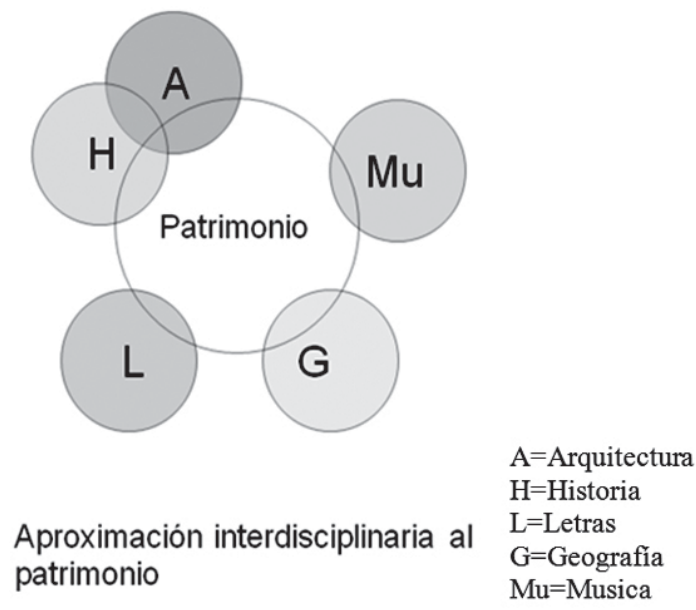

Fig. 3 Aproximación interdisciplinaria

Fuente: Elaboración propia

Según L. Flores estos espacios de encuentro generan la aparición de sub disciplinas que se encargan del análisis de objetos de estudio parciales (Flores 2011). Así, el acercamiento y superposición disciplinar entre la historia y la arquitectura, sin siquiera incorporar el patrimonio como objeto de estudio común, generarían la sub disciplina "historia de la arquitectura." Para el caso de estudio que se presenta, podría sostenerse que para comprender el patrimonio histórico arquitectónico, es necesaria una aproximación interdisciplinaria al objeto de estudio en cuanto requiere de "un esfuerzo indagatorio convergente." (Ibid) 


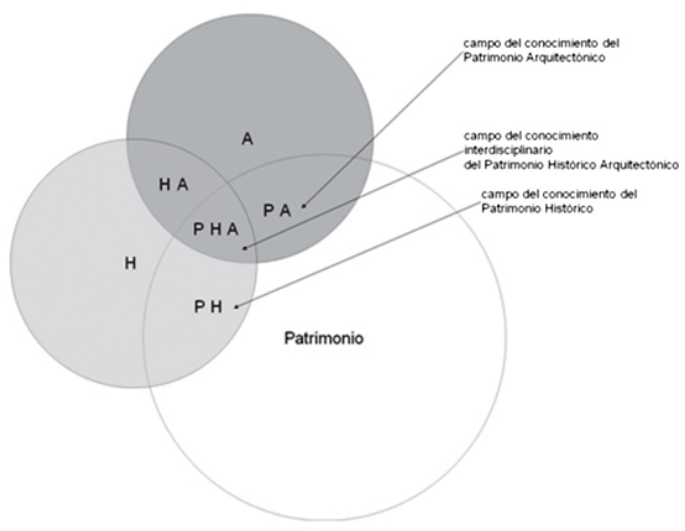

Fig. 4 Las subdisciplinas

Fuente: Elaboración propia

Más que un nuevo objeto de estudio, el patrimonio histórico arquitectónico, aparece como un objeto más específico, sin quedar fuera de un campo de conocimiento externo al conjunto mayor Patrimonio o a los conjuntos Arquitectura o Historia. Se trata de una parte de los estudios sobre el patrimonio que al ser más específico, tiene un campo de conocimiento limitado y requiere de una metodología particular. Así, por ejemplo, la Historia de la Arquitectura emerge como una sub disciplina de la Arquitectura y de la Historia, para concentrarse precisamente en el estudio de edificios, obras y ciudades que tienen una significación particular para la disciplina. Mientras, en este marco, la Historia de la Arquitectura contribuye a la valoración de ciertas obras con respecto a otras, se configura como sub disciplina que no es suficiente para el entendimiento cabal sino tan sólo parcial, para la valoración y creación del Patrimonio Histórico Arquitectónico. De este modo, se puede graficar cómo no todas las obras de arquitectura son parte del "subconjunto" patrimonio Arquitectónico, y no toda Historia se ocupa del patrimonio histórico, aún cuando para entender el patrimonio histórico arquitectónico es indispensable considerar una aproximación interdisciplinar en ciertas fases sin perjuicio, de que en otros casos dicha integración no supere la mirada multidisciplinar. (Ver figura 4)

Las disciplinas involucradas en el estudio que ha originado esta reflexión -la arquitectura, la historia y las ciencias de la educación- aportan con sus metodologías analíticas específicas en este proyecto de investigación. La arquitectura con el registro y definición de los parámetros morfológicos, espaciales o materiales que definen una obra o un espacio de la ciudad. La historia mediante la reflexión de las nociones de presente y pasado asociadas a los diferentes tipos de patrimonio y a la forma en que una sociedad entrega la connotación de "histórico" a un monumento. Por 
último, las ciencias de la educación como vehículo esencial en la transferencia activa de las habilidades asociadas tanto a la sensibilización del patrimonio en su sentido más amplio y también en la entrega de contenidos específicos presentes en los planes y programas actuales relativos al patrimonio cultural. En síntesis, el ejercicio de la naturaleza multidisciplinar o interdisciplinar del patrimonio como objeto de estudio, responde justamente a esa visión amplia, integradora y dinámica con la que se plantea el patrimonio como fenómeno.

Sobre la base de la consideración de integración disciplinar del fenómeno patrimonial y ante el desafío de reflexionar en torno a la educación patrimonial, es preciso examinar los actuales programas de estudios a nivel escolar. Tal revisión permite determinar en qué medida las diversas asignaturas, con menor o mayor articulación desde los nuevos planes y programas nacionales, se hacen cargo del tema patrimonial, por un lado, y si permiten comprender la visión integral del patrimonio que surge de la naturaleza interdisciplinaria del propio objeto de estudio.

\section{El patrimonio en los planes y programas nacionales}

"De todas las miradas, la educativa es una de ellas, fundamental para conseguir que el patrimonio sea conocido, comprendido, valorado y transmitido por la sociedad que lo recibe y que lo lega; por lo tanto, creemos que es una mirada absolutamente imprescindible.” (Calaf, Fontal

2006: 18)

Si valorar el patrimonio implica, de alguna forma, valorar la propia cultura, es preciso reconocer que para que tal valoración ocurra - individual o mediante una negociación colectiva-, el patrimonio se debe conocer. Y, para ello, no basta con que especialistas trabajen por identificarlo, valorarlo, intervenirlo y gestionarlo. La sociedad debe hacerlo en su conjunto para lo cual resulta fundamental plantear el tema de educación patrimonial, entendida ésta como un proceso formativo, que va más allá del aula, y que implica aprender a través de museos, centros de interpretación, rutas o del territorio mismo. En esta línea, autores han sostenido que la educación patrimonial no formal contribuye a la difusión del patrimonio (Estepa, Cuenza 2006). Como sea, cabe subrayar que antes de ser "aprehendido" por especialistas, el patrimonio se debe trabajar desde temprana edad.

No obstante la didáctica del patrimonio se ha propuesto como un proceso a desarrollar dentro y fuera del aula (Calaf, Roser 2009: 34), a continuación se examina la presencia de esta materia dentro del aula. Más concretamente, desde el aula y a través de la educación formal entendida como el ámbito donde "se refieren los proceso educativos que conducen a la obtención de títulos académicos regulados por las legislaciones educativas de un Estado.” (Colom 2001: 41) 
A inicios de la década de los noventa se inició un proceso de transformación del currículum en el sistema educacional chileno que dio un paso a un profundo cambio en distintas dimensiones. Entre ellas se destaca un nuevo tipo de normativa que regularizara el currículum escolar y un cambio en la estructura de los planes de estudio y su distribución horaria. Adicionalmente, se reorientaba “...el conjunto de las áreas que conforman el currículum para conducir a los estudiantes hacia aprendizajes más significativos y relevantes para el mundo actual” (Cox 2003: 213).

Este proceso de cambio estaba vinculado a la nueva sociedad del conocimiento la cual -según se indicaba- demandaba un sistema escolar que pudiera reunir elementos esenciales para formar a las nuevas generaciones, tales como lograr una mayor abstracción y elaboración de conocimientos; generar procesos de experimentación y aprender a aprender; lograr un mejor trabajo colaborativo; una mayor capacidad de resolución de problemas, entre otros (Ibid: 219).

Desde esa perspectiva se construyeron los Objetivos Fundamentales (OF) y Contenidos Mínimos Obligatorios (CMO) para la enseñanza Básica y Media los cuales debían responder a tres requerimientos. El primero, se refirió a la necesidad de actualizar, reorientar y enriquecer los curriculum producto de los cambios en el conocimiento y en la sociedad, con el fin de “...ofrecer a alumnos y alumnas conocimientos, habilidades y actitudes, relevantes para su vida como personas, ciudadanos y trabajadores, así como para el desarrollo económico, social y político del país.” (MINEDUC 2009) El segundo requerimiento, se relacionó a la necesidad de proporcionar una base cultural común a todo el país con el fin de favorecer “...la cohesión e integración social y que admita ser complementada para acoger la diversidad cultural del país.”(Ibid) Por último, un tercer requerimiento se concentró en mejorar la articulación de los niveles educativos de párvulos, básica y media, con el objetivo de “....asegurar una trayectoria escolar fluida y una calidad homogénea entre niveles, resguardando la particularidad de cada uno de ellos.”(Ibid) Tales demandas obligaron a fortalecer las políticas educacionales de Estado con el fin de mejorar la calidad de la educación, asegurando que todos pudieran alcanzar las metas planteadas en los programas en pos de una mayor equidad en el sistema y un compromiso de participación de toda la sociedad.

Considerando los principios inspiradores de las tres demandas mencionadas -relevancia del conocimiento, integración cultural y articulación de la enseñanza en todos sus niveles- surgen dos propósitos fundamentales para los OF y los CMO para la Enseñanza Básica y Media. El primero se vinculó al desarrollo personal "pleno de cada uno de los chilenos y chilenas, potenciando al máximo su libertad, creatividad, iniciativa y crítica” y, el segundo, se relacionó al desarrollo equitativo, sustentable y eficiente del país. (Ibid)

En este escenario se definieron los Planes de estudio de la educación chilena, lo que incluye una indicación de los tiempos de cada nivel 
escolar mientras se consignan las actividades curriculares de los estudiantes. Adicionalmente, los Programas de Estudios entregan una organización didáctica para cada nivel para el logro de los OF definidos en el Marco Curricular "En los programas de estudio del Ministerio de Educación se definen aprendizajes esperados, por semestre o por unidades, que corresponden a objetivos de aprendizajes acotados en el tiempo” (Ibid).

Considerando los fines propuestos por el sistema educacional chileno y, particularmente los propósitos de los OF y CMO tanto a nivel de enseñanza básica como enseñanza media, indagar sobre el paso del patrimonio desde objeto de estudio a contenido mínimo aparece como relevante y pertinente a los mismos. La didáctica del patrimonio permite no sólo sensibilizar sobre los bienes que una sociedad opta por resguardar sino también apunta a desarrollar un pensamiento crítico frente al medio en que la sociedad habita en pos de fortalecer la identidad cultural. Educar en el patrimonio permite promover valores que apoyan a la ciudadanía y que integran los objetivos transversales de la educación. ${ }^{7}$ En este sentido, el patrimonio, aparece como un vehículo para lograr ciertos objetivos transversales que responden a demandas tales como una mayor integración cultural.

Considerando las orientaciones sobre el conocimiento y el aprendizaje específico del currículum, se ha explorado la presencia de la temática patrimonial en el currículum chileno vigente en las diversas asignaturas. Tal indagación ha permitido, en primer lugar, evidenciar que la enseñanza del patrimonio está inserta en los distintos niveles de la educación tanto en enseñanza básica y media, y en las diversas asignaturas de forma más o menos explícita. En segundo lugar, se aprecia que existe un continuo en la progresión del aprendizaje a través de todos los niveles escolares en busca del logro de conocimientos, habilidades y actitudes para alcanzar o favorecer un desarrollo integral sobre el tema de patrimonio.

De esta forma, son varias las asignaturas que en el sistema educacional se encargan de contribuir al conocimiento del patrimonio. Diversas materias, desde sus propios campos de conocimiento y metodologías particulares, abordan aspectos de enseñanza en pos de alcanzar conocimientos específicos o transversales. Por tanto, se podría sugerir que la malla curricular básica y media, como estructura que articula los diversos conocimientos, es un punto de arranque para examinar la mirada amplia e integradora del patrimonio.

Si se observa con detención la presencia del patrimonio como contenido en la malla curricular tanto para los Planes y Programas de Enseñanza Básica (primaria) y Media (secundaria), se puede notar cómo esta materia aparece en forma explícita en los procesos de enseñanza y aprendizaje (Ver Figura 5). Especialmente si se consideran los distintos tipos de patrimonio y se incorporan tanto objetos oficialmente protegidos como aquellos que no cuentan con protección formal. 
Adicionalmente, se evaluaron los Objetivos Fundamentales Verticales (OFV) definidos como aquellos que todo estudiante debe lograr en cada uno de los niveles durante sus doce años de formación. Se consideraron los Contenidos Mínimos Obligatorios (CMO) en cuanto explicitan los conocimientos, habilidades y actitudes implicados en los Objetivos Fundamentales y que deben convertirse en oportunidades de aprendizaje en el proceso de enseñanza. Por último, y con el fin de proporcionar un panorama global y actualizado, esta revisión indica los ajustes que el marco curricular ha tenido en algunas áreas en los últimos años.

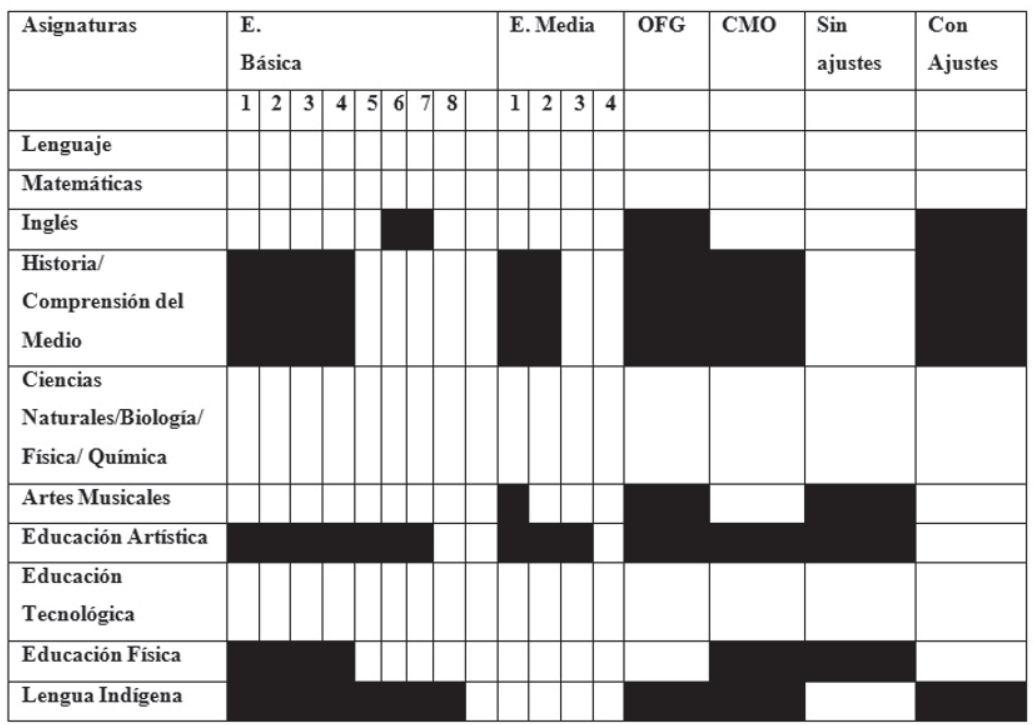

\section{Figura 5. Presencia del patrimonio en el marco curricular chileno}

Fuente: Elaboración propia basada en datos MINEDUC 2009.

La estructura del cuadro presentado como Figura 5 permite evidenciar que existe un vacío en las asignaturas de ciencias naturales, biología, física y química en la enseñanza del patrimonio. De ahí que un desafío obligado que surja de esta operación sea el de dar una segunda lectura a los contenidos en lo que el conocimiento y resguardo del entorno natural aparecen como una forma de aproximarse al estudio y protección del patrimonio natural.

Asimismo, si se observa en detalle la presencia de esta materia en las distintas asignaturas para Primero Medio, se evidencia cómo las asignaturas de Idioma extranjero, Ciencias Sociales, Artes musicales y Artes visuales en forma explícita indican objetivos fundamentales para la enseñanza del patrimonio intangible y, por tanto, de cómo lograr esos objetivos (Ver Figura 6). 
Polis, Revista Latinoamericana, Volumen 13, No 38, 2014

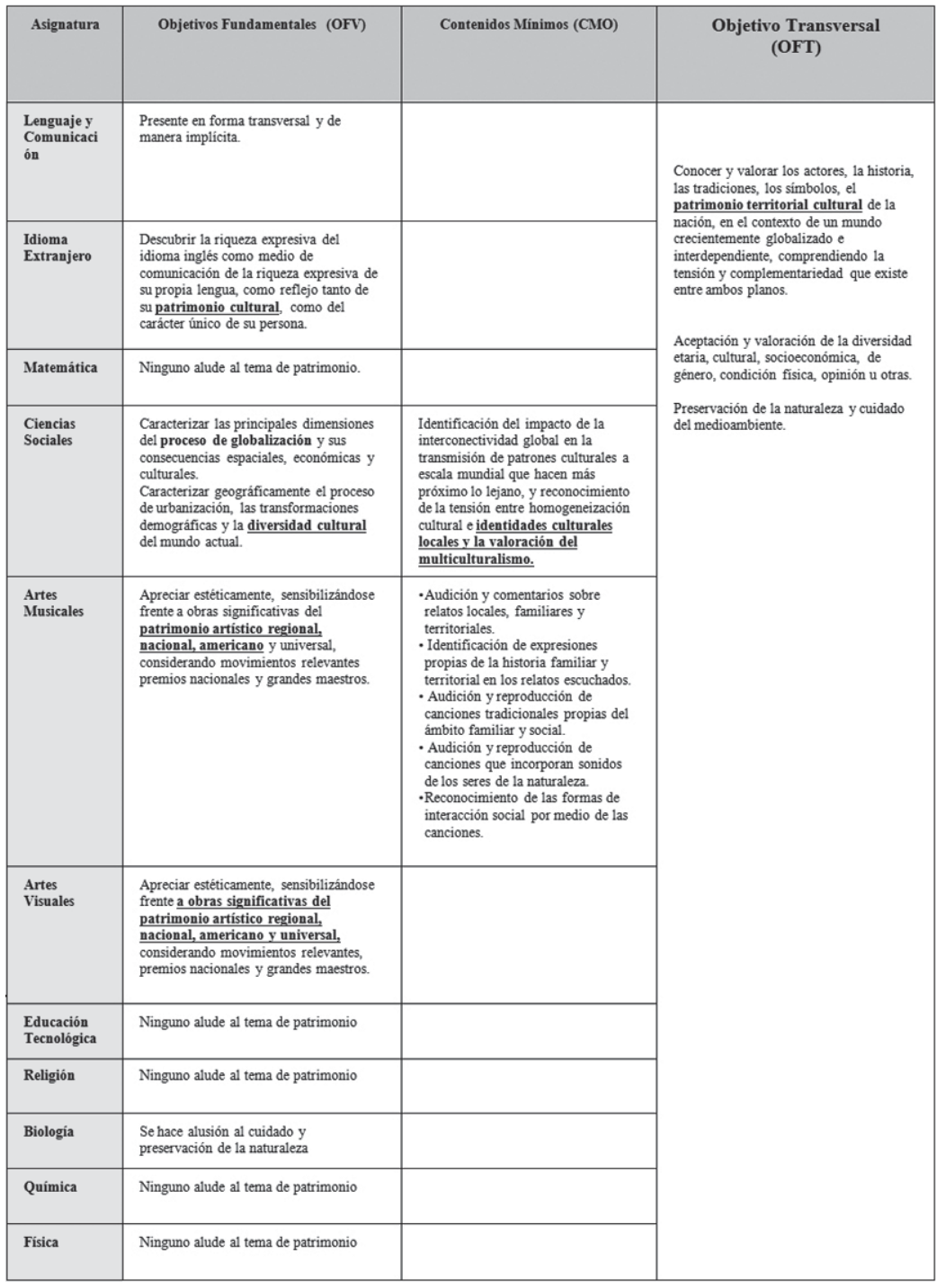

\section{Figura 6. Malla curricular de Primero Medio relevante para materia de patrimonio.}

Fuente: Elaboración propia basada en datos MINEDUC 2009.

En la misma línea, la malla curricular muestra cómo el patrimonio como objeto de estudio puede ofrecer valores y contenidos asociados a 
tres objetivos transversales vinculados al conocimiento del territorio; la aceptación y valoración de la diversidad cultural; y al cuidado de la naturaleza y medioambiente.

No obstante, la revisión del fenómeno patrimonial en términos amplios e integradores permite sugerir que aún quedan vacíos en distintas áreas en las que la educación patrimonial podría jugar un rol integrador y fortalecedor de ciertos valores y, a su vez, dotar al educando de herramientas de trabajo que integre varias disciplinas en pos de la formación de una persona con una mirada más amplia. Estas reflexiones resultan fundamentales a la hora de enfrentarse a los nuevos cambios curriculares que debieran asumir la dirección interdisciplinar que no sólo las ciencias sociales sino los diversos campos del conocimiento han tomado en las últimas décadas.

\section{Conclusiones}

Aun cuando no se pueden trazar fronteras rígidas, el patrimonio se debe entender como un fenómeno en el que convergen diversas miradas y, por lo tanto, se hacen cargo distintas disciplinas. Al surgir como un objeto de estudio compartido entre varios campos de conocimiento, el estudio del patrimonio no se puede completar sin una metodología de trabajo multidisciplinaria o interdisciplinaria. Estas aparecen no sólo como las más apropiadas sino como las más efectivas para conocer a cabalidad este objeto de estudio.

Un beneficio de la educación patrimonial es que deberá fortalecer la protección de bienes que no están protegidos oficialmente. Apuntar a que los distintos tipos de patrimonio se deben integrar, más aún, que existen incluso grados de dependencia entre uno y otro, es una consideración fundamental para su protección. De ahí que un importante desafío en el marco de la educación formal sea la elaboración de herramientas metodológicas que permitan vincular los contenidos relativos al patrimonio en las distintas asignaturas escolares. Esto implica acoger el desafío de recoger tanto aquellas materias que se refieren en forma explícita a su ámbito como a unidades que se identifican en forma tácita con contenidos que son parte del quehacer del patrimonio.

Por último, reflexionar sobre el patrimonio cultural implica reconocer como punto de partida el conocimiento de los habitantes sobre su territorio. De ahí que la formación de profesionales en esta materia no pueda considerarse como suficiente para asegurar la protección del patrimonio. El conocimiento de los especialistas -fundamental a la hora de plantear intervenciones- debe convivir con una educación patrimonial planteada desde las bases, pues es la sociedad civil en su conjunto quien elabora la construcción de esas significaciones. Por ello, más que sensibilizar a la comunidad sobre los alcances del patrimonio, es preciso alimentar el conocimiento, valoración, sentido crítico, amplio e inclusi- 
vo de este fenómeno a una sociedad cada día más participativa en la gestión de su patrimonio. De ahí que promover -a través de cambios significativos en los procesos de enseñanza y aprendizaje- la valoración del patrimonio en jóvenes estudiantes como sujetos activos en esta problemática sea una preocupación de especial vigencia. 


\section{Notas}

${ }^{1}$ Esta reflexión es producto del proyecto de investigación Educando en el Patrimonio. Hacia el fortalecimiento de la identidad cultural promovido y financiado por el primer Concurso de Investigación Interdisciplinaria de la Vicerrectoría de Investigación de la Pontifica Universidad Católica de Chile, año 2011.

2 Según el Diccionario de la lengua francesa, París, 1990: Patrimonio es un bien de herencia que se transmite de los padres y las madres a los hijos. Según el Diccionario de la Lengua de la Real Academia Española, el término puede tener las siguientes acepciones, entre otras: 1 . Hacienda que alguien ha heredado de sus ascendientes; 2. Conjunto de los bienes propios adquiridos por cualquier título; 3. Der. Conjunto de bienes pertenecientes a una persona natural o jurídica, o afectos a un fin, susceptibles de estimación económica.

${ }^{3}$ Cabezas, Angel, 2009.

${ }^{4}$ El proyecto realizado en el marco del Concurso de Políticas Públicas UC 2011, "Una nueva institucionalidad para la creación, mantención y conservación de parques urbanos” por S. Reyes, M. Ibarra y M. Miranda, propone como integrar el valor natural y cultural de los parques urbanos con el fin de avanzar hacia una mejor conservación de los mismos.

${ }^{5}$ Ley $\mathrm{N}^{\circ} 17.288$ de monumentos nacionales. La categoría santuarios de la naturaleza el año 2011 deja de estar a cargo del CMN.

${ }^{6}$ La Matanza del Seguro Obrero, consistió en la matanza a miembros golpistas del partido nacional socialista, pro-ibañistas, en el gobierno de Arturo Alessandri Palma el 5 de septiembre de 1938.

${ }^{7}$ Concepto de objetivos transversales. 


\section{Bibliografía}

Acuña, O. (2009), Ley $N^{\circ} 17.288$ de Monumentos Nacionales y Normas Relacionadas, Tercera edición actualizada, Santiago.

Barriga, Henríquez Guillermo, (2003), “La presentación del objeto de estudio. Reflexiones desde la práctica docente”, Cinta de Moebio, Revista Electrónica de Ciencias Sociales de la Facultad de Ciencias Sociales de la Universidad de Chile, Santiago.

Burke, P. (2001), Eyewitnessing: The Uses of Images as Historical Evidence, Cornell University Press, Ithaca, N.Y.

Calaf, Fontal (2006), Miradas al patrimonio, Trea, Gijón.

Calaf M. R. (2009), Didáctica del Patrimonio. Epistemología, metodología y estudio de casos, Trea, Gijón.

Carr, E.H. (1986), Qué es la historia, edición revisada por R.W. Davies, Penguin Harmondsworth.

Choay, F. (2007), Alegoría del Patrimonio, Gustavo Gili, Barcelona.

Colom, A. (2001), Teoría de la Educación, Editorial Síntesis, Madrid.

Cox, C. (2003), Políticas Educacionales en el cambio de siglo. Las reformas del sistema escolar de Chile, Editorial Universitaria, Santiago.

Dormaels, M. (2011), “Patrimonio, Patrimonialización e Identidad. Hacia una hermenéutica del Patrimonio”, en Revista Herencia, vol. 24, num. 1 y 2, Santiago de Chile.

Estepa, Cuenza (2006), “La mirada de los maestros, profesores y gestores del patrimonio. Investigación saobre concepciones acerca del patrimonio y su didáctica”, en Calaf y Fontal (Coords), Miradas del Patrimonio, Trea, Gijón.

Flores L. (2011), Conceptos epistemológicos de disciplina y modelos de interdisciplina. Ponencia presentada en el Primer Seminario de Interdisciplina UC, Pontificia Universidad Católica de Chile, Santiago.

Hidalgo R. (2004), La Vivienda Social en Chile y la Construcción del Espacio Urbano en el Santiago del Siglo XX, Dibam, Santiago de Chile.

Ibarra, Bonomo (2012), “De la Fábrica a la Vivienda. La protección de la memoria obrera en torno a la Fábrica Central de Leche, Santiago de Chile”, en revista Apuntes vol. 25, num. 1, Bogotá.

Ibarra, Ramírez, Bonomo, Vera (2011), ¿Qué hace a un objeto de estudio 
interdisciplinario?, Ponencia presentada en Seminario de Interdisciplina UC, Pontificia Universidad Católica de Chile, Santiago.

Norá, P. (2009), Lugares de la memoria, LOM, Santiago.

MINEDUC (2009), Modificación al Decreto Supremo $N^{\circ} 220$ de 1998, del Ministerio de Educación que establece los Objetivos Fundamentales y Contenidos Mínimos Obligatorios de la Educación Media y fija Normas Generales para su aplicación. $N^{\circ} 254$. Santiago.

Sotolongo, Delgado (2006), La revolución contemporánea del saber y la complejidad social: hacia unas ciencias sociales de nuevo tipo, CLACSO, Buenos Aires.

Recibido: 21.05.2013

Aceptado: 13.08.2014 